\section{AB0155 COMPARATIVE ANALYSES OF SEROLOGICAL BIOMARKERS AND DISEASE CHARACTERISTICS BETWEEN ELDERLY ONSET RHEUMATOID ARTHRITIS (EORA) AND YOUNGER ONSET RHEUMATOID ARTHRITIS (YORA)}

S. Rajalingham ${ }^{1}$, S. S. Shaharir ${ }^{1}$, H. Mahadzir ${ }^{1} .{ }^{1}$ Universiti Kebangsaan Malaysia, Medicine, CHERAS, Malaysia

Background: Several studies have reported differences in disease characteristics between elderly onset RA (EORA: age of onset $>60$ years) and younger-onset RA (YORA). However, the findings across the studies have been rather inconsistent owing partially to the genetic variation across the populations studied. While a few studies have looked into the clinical aspects of EORA, there is a profound lack of comparative data on serological findings between EORA and YORA. Seropositive RA is known to be associated with more aggressive disease and the titres of the autoantibodies may predict the disease activity and the severity of radiographic progression.

Objectives: The main aim of this study was to compare the levels of the autoantibodies namely anti-CCP (cyclic citrulinated peptide), IgA, IgM, IgG rheumatoid factors(RF) and disease characteristics between the EORA and YORA groups.

Methods: We consecutively recruited a total of 151 female RA patients who were tested for IgA RF, IgG RF, IgM RF and anti CCP antibodies. Participants were aged above 18 years and met the 2010 ACR/EULAR RA criteria. Data on the disease characteristics (age at onset, disease activity at onset, disease duration and medications)were obtained by reviewing the medical records of the subjects. Subjects were divided into 2 groups i.e EORA and YORA based on age at onset of RA. All subjects were assessed for the severity of radiographic joint damage and functional disability based on Modified Sharp Score (MSS) and Health-assessment questionnaire-disability index (HAQ- DI), respectively. The EULAR response criteria was used to determine the subjects' response to disease-modifying anti-rheumatic drugs.

Results: The EORA group had 69 patients whereas the YORA group had 82 patients. The mean anti-CCP and IgA RF levels were significantly higher in the YORA group with $p$ values of 0.002 and 0.035 , respectively. The YORA group had significantly more severe disease at onset ( $p$ value for DAS 28 at onset was 0.009 ) with worse radiographic joint damage ( $p$ value for MSS was 0.006 ). In parallel with these findings, the YORA group had significantly higher ESR and CRP at onset with higher frequency of subjects requiring advanced therapies. The differences in frequency of RF positivity, disease duration, number of DMARDs, prednisolone dose and HAQ-Di scores between the groups did not reach statistical significance.

Conclusion: EORA is characterized by lower levels of anti-CCP and IgA autoantibodies with less aggressive disease as compared to YORA.

REFERENCES:

[1] Calvo-Alen J, Corrales A, et al.Clinical rheumatology 2005;24:485-9.

[2] Huscher D, Sengler C, Ochs W, et al. Clinical and experimental rheumatology 2013;31:256-62.

[3] Mueller RB, Kaegi T, et al. Rheumatology 2014;53:671-7.

Table 1. Comparison of disease characteristics between EORA and YORA

\begin{tabular}{|c|c|c|c|}
\hline Parameter & EORA $(n=69)$ & YORA $(n=82)$ & $p$ value \\
\hline Age (years)* & $67.19 \pm 2.49$ & $31.93 \pm 5.10$ & $<0.050$ \\
\hline Disease duration (years) ${ }^{\star}$ & $8.06 \pm 5.04$ & $8.70 \pm 3.63$ & 0.365 \\
\hline DAS28 at onset ${ }^{*}$ & $3.29 \pm 1.37$ & $3.96 \pm 1.68$ & 0.009 \\
\hline RF positive at onset & $47(68.11)$ & $62(75.61)$ & 0.306 \\
\hline Anti CCP titre ${ }^{\star}$ & $84.52 \pm 117.97$ & $151.14 \pm 138.02$ & 0.002 \\
\hline IgA RF titre* & $24.15 \pm 39.54$ & $43.14 \pm 64.82$ & 0.035 \\
\hline IgM RF titre* & $68.58 \pm 97.65$ & $72.74 \pm 93.28$ & 0.789 \\
\hline IgG RF titre* & $64.36 \pm 66.01$ & $70.88 \pm 69.58$ & 0.558 \\
\hline ESR at onset $(\mathrm{mm} / \mathrm{hr})^{*}$ & $54.20 \pm 20.50$ & $67.04 \pm 23.60$ & 0.001 \\
\hline $\mathrm{CRP}$ at onset $(\mathrm{mmol} / \mathrm{L})^{*}$ & $1.33 \pm 1.37$ & $3.79 \pm 8.11$ & 0.019 \\
\hline \multicolumn{4}{|l|}{ No. of DMARDS } \\
\hline 1 & $45(65.21)$ & $41(50.00)$ & \multirow{3}{*}{0.106} \\
\hline 2 & $16(23.19)$ & 32 (39.02) & \\
\hline 3 & $8(11.59)$ & $9(10.98)$ & \\
\hline On biologics \& tsDMARD & $12(17.39)$ & 35 (42.68) & 0.008 \\
\hline Prednisolone dose $(\mathrm{mg})^{*}$ & $2.83 \pm 3.32$ & $2.77 \pm 3.02$ & 0.920 \\
\hline \multicolumn{4}{|l|}{ Treatment Response } \\
\hline Good & $50(72.46)$ & $54(65.86)$ & \multirow[t]{3}{*}{0.487} \\
\hline Moderate & 15 (21.74) & $19(23.17)$ & \\
\hline None & $4(5.80)$ & $9(10.98)$ & \\
\hline MSS* $^{*}$ & $10.04 \pm 12.79$ & $17.49 \pm 19.04$ & 0.006 \\
\hline$H A Q-D I^{*}$ & $1.47 \pm 0.87$ & $1.58 \pm 0.71$ & 0.397 \\
\hline
\end{tabular}

Data presented as either counts (percentages) or mean $\pm \mathrm{SD}^{\star}$

Disclosure of Interests: None declared

DOI: 10.1136/annrheumdis-2021-eular.1305

\section{AB0156 \\ INCIDENCE OF CERVICAL SPINE INVOLVEMENT IN RHEUMATOID ARTHRITIS, RESULTS FROM A SINGLE CENTRE OBSERVATIONAL STUDY}

A. Conforti', F. Bruno ${ }^{1}$, O. Berardicurti', V. Pavlych ${ }^{1}$, I. DI Cola' ${ }^{1}$, F. Sensini ${ }^{1}$, A. Barile ${ }^{1}$, C. Masciocchi ${ }^{1}$, P. Cipriani ${ }^{1}$, P. Ruscitti ${ }^{1} .{ }^{1}$ University of LAquila, Department of Biotechnological and Applied Clinical Sciences, L'Aquila, Italy

Background: Rheumatoid arthritis (RA) manifests as a chronic, symmetrical articular disease; any synovial joint may be involved and the cervical spine is another possible affected site $[1,2]$. Although the cervical spine involvement is a very severe complication of RA, the exact incidence of cervical spine abnormalities in RA is not fully elucidated yet.

Objectives: In this work, we aimed at evaluating the incidence of a cervical spine involvement and associated clinical characteristics in patients with RA in a single centre observational study.

Methods: In this study, we performed a retrospective analysis of prospectively followed-up patients with RA attending our Rheumatologic Clinic, University of L'Aquila, L'Aquila, Italy, between January 2010 and December 2020. Patients who met the diagnostic criteria of 1987 ACR and/or ACR/EULAR 2010 criteria were assessed. Each patient was investigated for cervical spine involvement occurrence, particularly the atlas-axis cervical involvement. Instrumental imaging evaluation of the cervical spine was performed in all patients with clinical suspicion of involvement, by both MRI and CT examinations. MRI examinations were performed on a 1.5 Tesla scanner, acquiring T1, T2, and STIR sequences on sagittal, coronal and axial planes. CT examinations were performed on a multidetecto 320-row CT scanner (Aquilion One,Toshiba) acquired with a thin collimation; soft tissue or bone algorithms were applied for image data reconstruction and analysis.

Incident cases of cervical spine involvement were reported as incidence proportion and incidence rate per 1000 person-years at risk.

Results: In this evaluation, 347 consecutive patients, (mostly female $87.6 \%$, mean age of $66.1 \pm 11$.3 years) attending our Rheumatologic Clinic, were studied The incidence proportion of cervical spine involvement was 2.0\% [0.6 - 3.4\%], occurring in 7 out of 347 patients, and identified by both MRI and CT scan. Considering over 1623 person-years, an incidence rate of $4.0 \times 1000$ [3.0 - 5.0] person-years was also estimated. All our patients with cervical spine involvement were characterised by female gender, rheumatoid factor, ACPA, fulfilment of ACR 1987 classificative criteria, and poorly controlled disease activity. Smoking habit and extra-articular manifestations were also frequently reported. Glucocorticoids, methotrexate, and infliximab were mainly administered in these patients. This therapeutic strategy resulted in a complete resolution of the inflammatory synovitis in all but one patient. The latter developed a cervical spinal instability resulting in neurological progression and required a subsequent surgical management.

Conclusion: The cervical spine involvement is an uncommon but serious manifestation of RA, since possibly causing severe neurologic damage. A poorly controlled inflammatory process would be an important risk factor for developing a cervical spine involvement in RA, thus, a proper management is required, from an early accurate recognition to a timely therapeutic strategy. MRI could provide a useful clinical tool to early evaluate the cervical spine involvement in RA Finally, considering the low incidence, further studies are needed to fully estimate the exact incidence of this manifestation, mostly in poorly symptomatic patients. REFERENCES:

[1] Shlobin NA, Dahdaleh NS. Cervical spine manifestations of rheumatoid arthritis: a review. Neurosurg Rev. 2020 Oct 10. Neurosurg Rev. 2020 Oct 10. doi: 10.1007/s10143-020-01412-1.

[2] Kothe, R.Rheumatoid instability in the cervical spine: Diagnostic and therapeutic strategies. Orthopade. 2018 Jun;47(6):489-495.

Disclosure of Interests: None declared

DOI: 10.1136/annrheumdis-2021-eular.1572

\section{AB0157 \\ PREVALENCE OF SARCOPENIA AND CLINICAL IMPLICATIONS IN NEWLY DIAGNOSED RHEUMATOID ARTHRITIS PATIENTS}

R. Ekici ${ }^{1}$, A. Erden², B. Özdemir², S. C. Güven², B. Armagan², Ö. Karakaş², K. Gok ${ }^{2}$, A. Omma ${ }^{2}$, O. Küçükșahin ${ }^{2}$, S. Erten ${ }^{2} .{ }^{1}$ Ankara Şehir Hastanesi, Internal Medicine, Ankara, Turkey; ${ }^{2}$ Ankara Şehir Hastanesi, Rheumatology, Ankara, Turkey

Background: The aim of this study is to determine the frequency of sarcopenia at the time of diagnosis in RA patients, evaluate the effects of sarcopenia on RA disease activity, prognosis and examine the factors that may be associated with sarcopenia.

Objectives: To determine the frequency of sarcopenia at the time of diagnosis in rheumatoid arthritis (RA) patients, assessing disease activity and factors that may be associated with sarcopenia and observe effects of treatment on sarcopenia. 
Methods: A prospective study was conducted on RA patients with newly diagnosed. Patients were evaluated twice, at the time of diagnosis and three months after the initiation of treatment. Demographic data, anthropometric measurements, disease activity scores and sarcopenia status were recorded. Sarcopenia was evaluated with grip strength and bioelectric impedance. The results were also compared with healthy volunteers.

Results: Hand grip strength $(p<0.001)$, skeletal muscle mass $(p=0.009)$ and skeletal muscle mass index $(p=0.032)$ were found to be reduced in RA patients compared to the control group. The frequency of sarcopenia in RA at onset of diagnosis was found to be $31.5 \%$. There was a significant decrease in the rate of sarcopenia after three months of treatment $(31.5 \%$ versus $8.7 \% ; p=0.046)$.

Conclusion: Sarcopenia was found in approximately one third of the patients with newly diagnosed RA in our study. With treatment, sarcopenia improved significantly. RA patients should be evaluated in terms of sarcopenia besides evaluating joint and extra-articular findings at the time of diagnosis. Early detection and treatment planning may improve the quality of life.
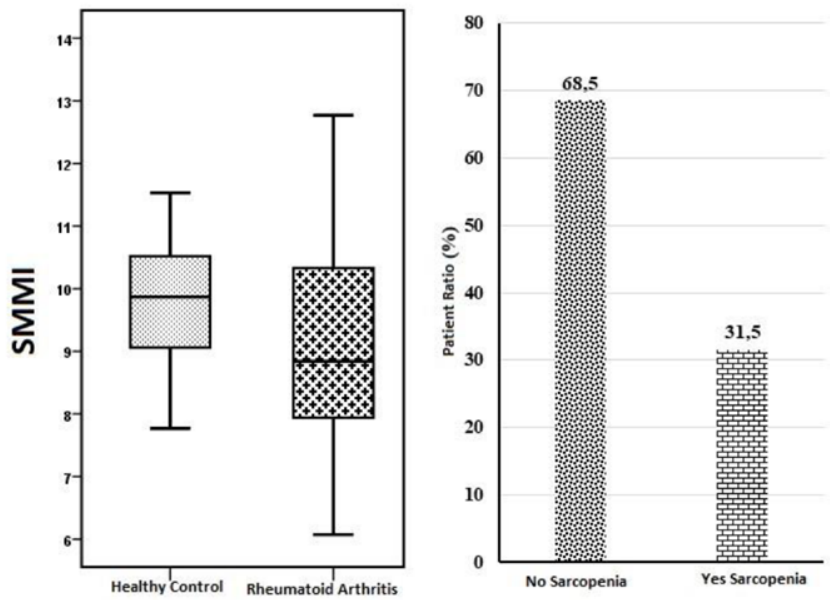

Figure 1. Distribution of skeletal muscle mass index (SMMI) and prevalence of sarcopenia in RA and control groups

Table 1. Demographics, clinical features, anthropometric measurements and disease activity scores of sarcopenic and non-sarcopenic RA patients

\begin{tabular}{|c|c|c|c|}
\hline & $\begin{array}{l}\text { RA without } \\
\text { sarcopenia } \\
n=37\end{array}$ & $\begin{array}{l}\text { RA with } \\
\text { sarcopenia } \\
\mathrm{n}=17\end{array}$ & p \\
\hline Age, mean (SD), years & $47,3(12,8)$ & $58,0(16)$ & $0,011^{*}$ \\
\hline Gender, female, n (\%) & $27(73)$ & $9(52,9)$ & 0,215 \\
\hline Marital status, married, $\mathrm{n}(\%)$ & $34(91,9)$ & $13(76,5)$ & 0,258 \\
\hline \multicolumn{4}{|l|}{ Tobacco consumption, $\mathrm{n}(\%)$} \\
\hline Active smoker & $10(27)$ & $5(29,4)$ & \multirow[t]{3}{*}{0,086} \\
\hline Ex-smoker & $8(21,6)$ & $8(47,1)$ & \\
\hline Never smoker & $19(51,4)$ & $4(23,5)$ & \\
\hline \multicolumn{4}{|l|}{ Alcohol consumption, $\mathrm{n}(\%)$} \\
\hline Active drinker & $2(5,4)$ & $2(11,8)$ & \multirow{3}{*}{0,244} \\
\hline Ex-drinker & $0(0,0)$ & $1(5,9)$ & \\
\hline Never drinker & $35(94,6)$ & $14(82,4)$ & \\
\hline \multicolumn{4}{|l|}{ Occupation, n (\%) } \\
\hline Worker & $15(40,5)$ & $12(70,6)$ & 0,060 \\
\hline Height, mean (SD), meter & $1,6(0,1)$ & $1,6(0,1)$ & 0,664 \\
\hline Weight, mean (SD), kg & $80,6(17,7)$ & $65,3(8,6)$ & $<0,001^{*}$ \\
\hline BMI, mean (SD), $\mathrm{kg} / \mathrm{m}^{2}$ & $31,4(7,3)$ & $24,9(3,2)$ & $<0,001^{*}$ \\
\hline Obese, n (\%) & $20(54,1)$ & $2(11,8)$ & $0,006^{\star}$ \\
\hline Waist circumference, mean (SD), cm & $97,1(14,2)$ & $89,3(12,8)$ & 0,058 \\
\hline Hip circumference, mean (SD), cm & $108,1(12,7)$ & $96,6(5,1)$ & $0,001^{*}$ \\
\hline Calf circumference, mean (SD), cm & $35,4(5,1)$ & $29,6(4,0)$ & $<0,001^{*}$ \\
\hline $\begin{array}{l}\text { Triceps skin thickness, median (min- } \\
\text { max), mm }\end{array}$ & $22(8-36)$ & $15(6-31)$ & $0,022^{*}$ \\
\hline \multicolumn{4}{|l|}{ Loss of muscle strength, $n(\%)$} \\
\hline Right & $10(27,0)$ & $9(52,9)$ & 0,076 \\
\hline Left & $12(32,4)$ & $10(58,8)$ & 0,081 \\
\hline Dominant hand, right, $\mathrm{n}(\%)$ & $33(89,2)$ & $13(76,5)$ & 0,418 \\
\hline SMM, mean (SD) & $25,1(5,8)$ & $21,9(4,7)$ & $0,049^{*}$ \\
\hline SMMI, mean (SD) & $9,6(1,5)$ & $8,2(1,2)$ & $<0,001^{*}$ \\
\hline DAS 28 - CRP, median (min-max) & $4,4(1,7-6,5)$ & $4,4(2,4-6,3)$ & 0,860 \\
\hline SDAI, median (min-max) & $36,1(8,8-113)$ & $31,1(17,1-113)$ & 0,668 \\
\hline CDAl, median (min-max) & $23(0-48)$ & $23(6-39)$ & 0,993 \\
\hline PrGA, median (min-max) & $6(0-9)$ & $5(2-10)$ & 0,627 \\
\hline PtGA, median (min-max) & $8(0-10)$ & $7(4-10)$ & 0,666 \\
\hline Presence of morning stiffness, $n(\%)$ & $32(86,5)$ & $14(82,4)$ & 0,999 \\
\hline Swollen joint count, median (min-max) & $2(0-10)$ & $4(0-9)$ & 0,423 \\
\hline Tender joint count, median (min-max) & $6(0-20)$ & $7(0-18)$ & 0,911 \\
\hline
\end{tabular}

Disclosure of Interests: None declared

DOI: 10.1136/annrheumdis-2021-eular.1874

\section{AB0158 \\ COMPARISON OF CLINICAL EXAMINATION AND ULTRASOUND OF HAND AND WRIST JOINTS IN RHEUMATOID ARTHRITIS}

S. Bouden ${ }^{1}$, B. D. Siwar ${ }^{1}$, A. Ben Tekaya ${ }^{1}$, O. Saidane ${ }^{1}$, R. Tekaya ${ }^{1}$,

I. Mahmoud ${ }^{1}$, L. Abdelmoula ${ }^{1} .{ }^{1}$ Charles Nicolle Hospital, Department of Rheumatology, Tunis, Tunisia

Background: Ultrasound (US) is an accessible and non-invasive tool to assess joint involvement in rheumatoid arthritis (RA). It is used for diagnostic and prognosis purposes and for following of RA patients by evaluating the disease activity and therefore the response to treatment.

Objectives: This study investigates agreement between US of hand and wrist findings and the clinical examination and biological inflammatory parameters in RA patients.

Methods: We performed a cross sectional study including patients responding to the ACR/EULAR 2010 criteria for RA diagnosis. We collected US findings assessing synovitis and doppler signal in wrist, metacarpophalangeal (MCP) and proximal interphalangeal (PIP) articulations, and concomitant clinical examination assessing synovitis and pain in the same joints along with $C$ reactive protein (CRP) levels and disease activity score (DAS28). The power Doppler US score (PDUS) from 6 simplified synovial sites (wrists, bilateral second and third MCP joints) was calculated [1].

Results: Forty-three patients were included with $91.7 \%$ of women. The mean age was $62 \pm 12.95$ years old. The mean age at diagnosis was $52 \pm 14.79$ years with a mean disease evolution of $8 \pm 8.57$ years. Rheumatoid factor and anti-citrullinated antibodies were positive in respectively $78 \%$ and $83.9 \%$ of cases.

The mean disease activity (DAS28) was 1,52 with levels ranging from 1.5 to 7.33. Right wrist was the articulation in which US synovitis was most frequently detected (60.5\% of patients), followed by the left wrist (53.5\%). Power doppler signal was detected as frequently in the right as in the left wrist articulations (41.9\%). Subsequently, clinical synovitis was most frequently detected in right and left wrist with $39,5 \%$ and $41,5 \%$ respectively. These joints were the most frequently painful, in $51.2 \%$ and $48.8 \%$ at right and left respectively.

US synovitis of the first interphalangeal joint was found in only $2.3 \%$ and $4.7 \%$ in the right and left hand respectively, with positive power doppler signal in $2.3 \%$ of the patients in the same articulations.

The overall agreement between US and clinical examination in detecting synovitis of wrist, MCP and PIP joints was of $67.3 \%$. It was of $71.4 \%$ in wrists, $54.7 \%$ in MCP joints and $87 \%$ in PIP joints. This suggests the presence of infra-clinical synovitis. All sites combined, US synovitis were correlated to clinical synovitis $(p=0.03)$.

A positive correlation was found between PDUS from 6 simplified joint sites and CRP levels ( $p$ value of 0.02 ). No correlation was found with disease activity score (DAS28).

Conclusion: US of hands and wrist articulations is more performant than clinical examination in detecting synovitis. The most frequently involved joints with clinical and US synovitis, pain and positive power doppler signal were the wrist joints. CRP level is predictive of the presence of a high simplified power doppler score which is related to clinical activity of the disease as reported by Kawashiri et al. [1].

\section{REFERENCES:}

[1] Kawashiri S, Kawakami A, Iwamoto N, Fujikawa K, Satoh K, Tamai M, et al. The power Doppler ultrasonography score from 24 synovial sites or 6 simplified synovial sites, including the metacarpophalangeal joints, reflects the clinical disease activity and level of serum biomarkers in patients with rheumatoid arthritis. Rheumatology (Oxford). mai 2011;50(5):962-5.

Disclosure of Interests: None declared

DOI: 10.1136/annrheumdis-2021-eular.1922

\section{AB0159 DIASTOLIC DYSFUNCTION IN PATIENTS WITH RHEUMATOID ARTHRITIS}

S. Cabrera-Villalba ${ }^{1}$, V. Valinotti ${ }^{1}$, L. Roman ${ }^{1}$, A. Paats ${ }^{1}$, P. DE Abreu Trigueros ${ }^{2}$, M. Duarte ${ }^{1}$, T. Martinez ${ }^{3}$, I. Acosta-Colman ${ }^{1}$, G. Avila ${ }^{1}$, O. Centurion ${ }^{4} .{ }^{1}$ Clinicas Hospital, Universidad Nacional de Asuncion, Rheumatology, San Lorenzo, Paraguay; ${ }^{2}$ Sociedad Paraguaya de Reumatolog ía, Rheumatology, Asunción, Paraguay; ${ }^{3}$ Asunción, Laboratorio Curie, Asunción, Paraguay; ${ }^{4}$ Clinicas Hospital, Universidad Nacional de Asuncion, Cardiovascular Medicine, Asunción, Paraguay

Background: Rheumatoid arthritis (RA) presents with an elevated incidence of congestive heart failure disease, which has a strong association with diastolic dysfunction, defined by left ventricular delayed relaxation pattern assessed by echocardiography. $(1,2)$

Objectives: To describe the frequency of left ventricular delayed relaxation pattern in patients with RA, and the relationship with its clinical and serologica characteristics, as well as with traditional and non-traditional cardiovascular risk factors. 